\title{
Produção de Ovinos em Gestação e Lactação sob Pastejo em Diferentes Estádios Fenológicos de Azevém Anual ${ }^{1}$
}

\section{Carlos Eduardo da Silva Pedroso ${ }^{2}$, Renato Borges de Medeiros ${ }^{3}$, Marcelo Abreu da Silva ${ }^{3}$, João Batista Jornada da Jornada ${ }^{2}$, João Carlos de Saibro ${ }^{4}$, José Roberto Funck Teixeira ${ }^{5}$}

\begin{abstract}
RESUMO - O experimento foi conduzido em uma área de 5,4 ha de azevém anual (Lolium multiflorum Lam.), dividida em quatro potreiros de dimensões similares. Os animais utilizados foram ovinos da raça Corriedale, ao final da gestação e início de lactação, que permaneceram no experimento no período de 3 de julho a 18 de novembro de 2000, onde foram realizadas avaliações em três estádios fenológicos: vegetativo (E1), pré-florescimento (E2) e florescimento (E3). Os animais foram mantidos em pastejo contínuo, com lotação variável de forma a manter-se uma oferta de matéria seca (MS) em torno de $15 \%$ do peso vivo animal (PV). Foram determinados o ganho de PV/ha, o ganho médio diário (GMD) e a carga animal. Como resultado das avaliações, observou-se oferta média de MS de folhas verdes de 7,2\% do PV sendo que, no final do ciclo, a porcentagem de colmos e material morto foi mais elevada, dificultando a ação seletiva dos animais. Este declínio progressivo na qualidade da pastagem também foi verificado no teor de proteína bruta, que decresceu de $23,7 \%$ no E1 para 19,4\% no E3 e da digestibilidade in vitro da matéria orgânica, que decresceu de 80,55\% no E1 para 60,70\% no E3. Em resposta a esta condição da pastagem, observaram-se adequados GMD, tanto para as ovelhas ( $103 \mathrm{~g} \mathrm{e} 87 \mathrm{~g}$ ) como para os cordeiros ( $289 \mathrm{~g}$ e $279 \mathrm{~g}$ ) nos estádios vegetativo e pré-florescimento. Por outro lado, no estádio de florescimento, os ganhos diários decresceram para ovelhas (-112 g) e cordeiros $(89 \mathrm{~g})$. Estes resultados evidenciaram o alto potencial do azevém anual em termos de ganho de PV nos estádios vegetativo (225 kg/ha) e pré-florescimento $(145 \mathrm{~kg} / \mathrm{ha})$. Todavia, a redução da qualidade da forragem no estádio de florescimento inviabiliza sua utilização para a produção de animais de alta exigência.
\end{abstract}

Palavras-chave: azevém, estádios fenológicos, gestação, lactação, ovinos, produção animal

\section{Sheep Production at the Pregnancy and at the Lactation under Grazing on Annual Ryegrass Pastures at Different Phenological Stages}

\begin{abstract}
The study was carried out in an experimental area of 5.41 ha, split in four paddocks of similar size. The performance of Corriedale breed animals at the end of pregnancy and at the beginning of lactation were evaluated from July 3 to November 18 , 2000 under grazing in three phenological stages of annual ryegrass (Lolium multiflorum Lam.): vegetative (E1), pre-flowering (E2) and flowering (E3). The animals were maintained in a continuous grazing, with variable stocking rates aiming at maintaining an offer of dry matter (DM) around $15 \%$ of live weight $(\mathrm{LW})$. The live weight gain (LWG), average daily gain (ADG) and the stocking rates were determined. The results showed a DM offer of green leaves of $7.2 \%$ of $\mathrm{LW}$, whereas at $\mathrm{E} 3$ the percentage of stems and dead material were higher, limiting the animal selective action. This continuous decrease in pasture quality was also recorded for crude protein percentage, that decreased from $23.7 \%$ in E1 to $19.4 \%$ in E3 and in vitro organic matter digestibility, which decreased from $80.55 \%$ in E1 to $60.70 \%$ in E3. In response to this pasture condition, it was observed a satisfactory ADG as much for sheep (103 g and $87 \mathrm{~g}$ ) as for lambs $(289 \mathrm{~g}$ and $279 \mathrm{~g})$ in the vegetative and in the pre-flowering stages. However, at the flowering stage, the daily gain decreased for sheep $(-112 \mathrm{~g})$ and lambs ( $89 \mathrm{~g})$. These results showed the high potential of the annual ryegrass in terms of live weight gain at the vegetative ( $225 \mathrm{~kg} / \mathrm{ha})$ and at the pre-flowering stages (145 $\mathrm{kg} /$ ha). However the forage quality reduction at the flowering stage do not allowed its utilization for animal of high nutrient requirement.
\end{abstract}

Key Words: animal production, annual ryegrass, lactation, phenological stages, pregnancy, sheep

\section{Introdução}

Desde o início da colonização no Sul do Brasil, a produção de ovinos vem contribuindo para seu desenvolvimento social e econômico. O sucesso desta atividade decorreu da existência de extensas áreas cobertas por pastagem natural no Estado do Rio Grande do Sul. Entretanto, apesar de sua produção e

\footnotetext{
${ }^{1}$ Parte de Dissertação de Mestrado do primeiro autor. Apoio: CAPES/CNPq e FAPERGS.

${ }^{2}$ Aluno de Mestrado, DPFA, Fac. de Agronomia, UFRGS (cepedroso@terra.com.br).

3 Prof. Adjunto, DPFA, Fac. de Agronomia, UFRGS (medeiror@orion.ufrgs.br).

${ }^{4}$ Prof. Adjunto, Colaborador Convidado e pesquisador do CNPq, DPFA, Fac. de Agronomia, UFRGS (jsaibro@zaz.com.br).

5 Aluno de Mestrado, Fac. de Veterinária, UFRGS.
} 
qualidade serem satisfatórias no período primavera/ verão, no período outono/inverno a ocorrência de baixas temperaturas diminui ou paralisa o crescimento das plantas. Neste último período, os campos naturais da maioria das propriedades do Estado apresentam-se superpastejados e sem condições de atender às exigências nutricionais dos animais. Como resultado, observam-se baixas taxas de natalidade dos animais de cria, uma vez que este período de escassez coincide com as fases de gestação e lactação dos rebanhos. No caso dos ovinos, a mortalidade de cordeiros após o parto é uma das causas mais importantes da baixa eficiência reprodutiva observada. Scales et al. (1986) relatam que este fenômeno se deve, em grande parte, à existência de fetos mal nutridos no terço final de gestação que, ao nascer, são expostos a intempéries, comumente observadas no Sul do Brasil, como geadas e fortes chuvas. Assim, torna-se fundamental a oferta de uma dieta de alta qualidade e quantidade não-limitante para atender às elevadas necessidades nutricionais que ocorrem durante este período. Segundo Beattie \& Tompson (1989), as necessidades de uma ovelha nestas condições são supridas com níveis de oferta de forragem próximos ao dobro do necessário para uma ovelha não-lactante.

Entre as possibilidades de preenchimento da lacuna ocasionada pela sazonalidade forrageira, o uso de espécies de estação fria, como o azevém anual (Lolium multiflorum Lam.), tem sido bastante indicado. Avaliações realizadas com esta espécie forrageira sob pastejo de cordeiros, evidenciaram altos ganhos de peso animal em curtos períodos de utilização (Canto et al., 1999). No entanto, pouco se sabe sobre o desempenho de ovelhas nas fases de gestação e lactação ao longo do ciclo de crescimento do azevém anual, pois, no decorrer dos diferentes estádios fenológicos, há diminuição gradual dos teores de carboidratos não-estruturais e aumento dos teores de celulose, hemicelulose e lignina, determinando, de forma também gradual, o decréscimo da qualidade da forragem (Blaser, 1964).

Nesse contexto, no presente trabalho, buscou-se avaliar o potencial produtivo de ovelhas no final da gestação e início de lactação, com seus respectivos cordeiros, sob pastejo de azevém anual nos diferentes estádios de desenvolvimento da pastagem.

\section{Material e Métodos}

O experimento foi conduzido em 2000, em uma área de 5,4 ha de azevém anual cv. Comum RS, dividida em quatro potreiros de área similar. O solo, pertencente à unidade de mapeamento Arroio dos Ratos, classe taxonômica plintossólo, é considerado de baixa fertilidade (Mello et al., 1966). Para o estabelecimento da pastagem, utilizou-se o preparo convencional do solo, fazendo-se a correção $(2,5$ t/ha de calcário dolomítico) e adubação $(200 \mathrm{~kg} / \mathrm{ha}$ da fórmula 5-20-20, mais $20 \mathrm{~kg} / \mathrm{ha}$ de $\mathrm{N}$ na forma de uréia). Como adubação em cobertura, utilizaram-se $140 \mathrm{~kg}$ de $\mathrm{N}$ na forma de uréia, distribuídos em quatro parcelas iguais, sendo a primeira após o perfilhamento (14/06) e as três seguintes nos dias 08/08, 30/08 e 22/09, por ocasião das pesagens dos animais.

Foram utilizadas ovelhas da raça Corriedale no final da gestação e início de lactação, com seus respectivos cordeiros. A prenhês do rebanho foi identificada por meio de diagnóstico de gestação efetuado aos 50 e aos 100 dias após o término da estação de monta, utilizando-se o aparelho de ultrasonografia. Em seguida, foi feita a estratificação dos animais por peso, sendo os mesmos divididos de maneira aleatória nos quatro potreiros, onde permaneceram de 3 de julho a 18 de novembro de 2000. A condução dos animais em pastejo contínuo com lotação variável foi realizada de forma a manterse uma oferta de forragem em torno de $15 \%(15 \mathrm{~kg}$ MS/100kg de PV/dia), ajustada pela técnica de put-and-take (Mott \& Lucas, 1952).

As avaliações foram realizadas nos seguintes estádios de desenvolvimento da pastagem: estádio vegetativo (E1), pré-florescimento (E2) e florescimento (E3), determinados por intermédio da escala de Moore et al. (1991). Em intervalos semanais, foram retiradas 16 amostras compostas por quatro linhas de $30 \mathrm{~cm}$ da pastagem com a finalidade de identificar nos perfilhos principais (três a cinco mais vigorosos) o momento de transição entre os estádios fenológicos. A presença de afilhos principais com nós visíveis ou palpáveis permitiu a determinação da mudança de estádio de E1 para o E2 (Tabela 1).

$\mathrm{O}$ momento de passagem entre o E2 e início do E3 foi verificado pela combinação entre a porcentagem de perfilhos com nós palpáveis ou visíveis e a emissão das primeiras panículas. Estes dois momentos de transição foram associados à graus dias de crescimento (GDC) obtidos pela fórmula (GDC $=[$ “(Tmax.+ Tmin $) / 2]$ Tbase $)$ com Tbase $=$ zero, a partir de dados coletados, registrados e armazenados por registradores de temperatura (datalogger tipo HOBO Proseries, Onset Computers), colocados no interior do dossel. 
A disponibilidade de forragem foi avaliada por intermédio da técnica da dupla amostragem, com a utilização do disco graduado. Para estimar a produção de MS para o período seguinte, utilizou-se a técnica de gaiolas emparelhadas, descrita por Klingman et al. (1943), associada ao triplo emparelhamento (Moraes et al., 1990), com três gaiolas por repetição. Simultaneamente, foi determinada a qualidade da forragem disponível por meio da separação botânica das frações folhas, colmo e material morto que, após secas em estufa, foram submetidas à análise de digestibilidade in vitro da matéria orgânica (DIVMO) e proteína bruta $(\mathrm{PB})$.

Para avaliação da produção animal foram realizadas pesagens dos animais a cada três semanas, aplicando-se um jejum de sólidos e líquidos por 12 horas antes de cada determinação. A partir destes dados, foram calculados o ganho de peso médio diário (GMD), carga animal (CA) e o ganho de peso vivo por ha (GPV/ha). O GMD dos animais foi calculado pela diferença entre o peso médio final e o peso médio inicial dos animais testers, dividido pelo período (em dias) que permaneceram na pastagem. A CA foi obtida pelo somatório dos pesos de todos os animais presentes em cada potreiro, dividido pela área de cada um deles, sendo os valores expressos em $\mathrm{kg}$ de $\mathrm{PV} /$ ha. O GPV/ha foi estimado pelo ganho médio diário dos animais testers multiplicado pelo número de animais e pelo número de dias. Os dados foram submetidos à análise de variância, tendo-se os períodos como tratamentos e os potreiros e seus respectivos grupos de animais como repetições. A comparação de médias foi realizada pelo teste de DMS a $5 \%$ de significância.

\section{Resultados e Discussão}

No presente estudo, observou-se uma adequada oferta de folhas verdes durante o período experimental (Figura 1), resultando em média de 5,5\% do PV. Valores bastante próximos a este $(5,92$ a $7,98 \%$ do PV) foram indicados por Pontes et al. (2003), em trabalho também realizado na EEA-UFRGS, como forma de maximizar a eficiência de utilização de pastagens de azevém anual sob pastejo de cordeiros.

Entretanto, apesar de serem mantidas ofertas de folhas verdes semelhantes ao longo do ciclo de crescimento da pastagem, a porcentagem de folhas diminuiu com relação a colmos durante este mesmo

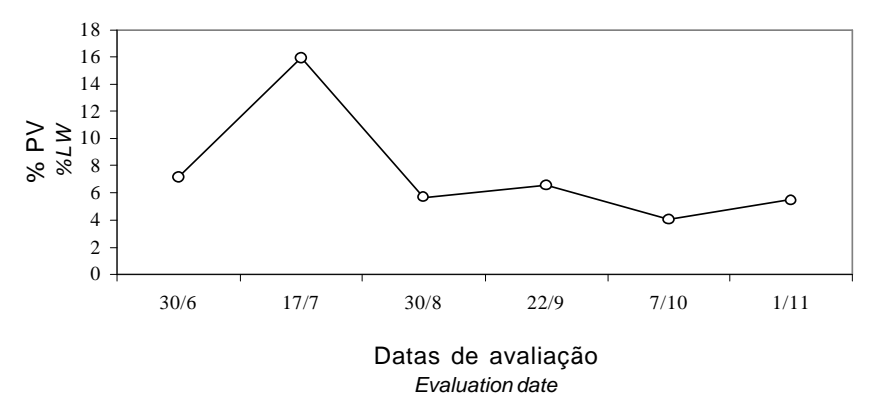

Figura 1 - Oferta de folhas verdes ( $\mathrm{kg}$ de MS de folhas verdes $/ 100 \mathrm{~kg}$ de $\mathrm{PV}$ animal/dia) de azevém anual durante o período de avaliação na pastagem.

Figure 1 - Offer of annual ryegrass green leaves ( $\mathrm{kg}$ of D.M. of green leaves $/ 100 \mathrm{~kg}$ of $L W$ animal/day) during the evaluation period.

Tabela 1 - Porcentagem de nós palpáveis ou visíveis dos perfilhos principais por ocasião do início dos estádios fenológicos do pré-florescimento e florescimento e graus dias de crescimento (GDC) na pastagem de azevém anual

Table 1 - Percentage of palpable or visible nodes in the principal tillers at the initiation of pre-flowering and flowering phenological stages and accumulation degree days in annual ryegrass pasture

\begin{tabular}{lccc}
\hline $\begin{array}{l}\text { Transição de estádios } \\
\text { Transition stages }\end{array}$ & $\begin{array}{c}\text { Data } \\
\text { Date }\end{array}$ & $\begin{array}{c}\text { Nós palpáveis }(\%) \\
\text { Palpable nodes }(\%)\end{array}$ & $\begin{array}{c}\text { GDC }\left({ }^{\circ} \mathrm{C}\right) \\
G D D\left({ }^{\circ} \mathrm{C}\right)^{1}\end{array}$ \\
\hline $\begin{array}{l}\text { Pré-florescimento } \\
\begin{array}{l}\text { Pre-flowering } \\
\text { Florescimento }\end{array}\end{array}$ & $23 / 09$ & 75 & 2144 \\
$F_{\text {Flowering }}{ }^{2}$ & $08 / 10$ & 90 & 2422
\end{tabular}

\footnotetext{
1 Growing degree days.

2 Primeiras panículas visíveis.

2 First visible panicles.
}

R. Bras. Zootec., v.33, n.5, p.1345-1350, 2004 
período. Na primeira avaliação, feita durante o estádio vegetativo da pastagem, foi obtida uma relação folha/ colmo de 4,36:1, enquanto, na última avaliação no estádio de florescimento, a relação caiu para 0,17:1 (Figura 2). Segundo Armstrong et al. (1995), existem evidências de que esta alta incidência de colmos no final do ciclo da cultura dificulta a seleção de folhas verdes pelos animais.

Com o avanço do desenvolvimento fenológico das plantas verificou-se, além da menor participação, a redução na qualidade das folhas verdes. Na primeira data de avaliação do estádio vegetativo, obtiveramse teores de $36 \%$ de proteína bruta (PB) e $88 \%$ de digestibilidade in vitro da matéria orgânica (DIVMO), enquanto, no estádio de florescimento, estes valores decresceram para 23 e $59 \%$ nos teores de PB e DIVMO, respectivamente (Figura 3).

Esta condição da pastagem refletiu no desempenho dos animais durante todo o período experimental. As ovelhas, nas duas primeiras avaliações no início do estádio vegetativo, tiveram GMD de 164 e 265 g, respectivamente, para a primeira e segunda avaliações (Figura 4). Com o início das parições, durante o terceiro período de avaliação, houve menor GMD das ovelhas (109 g), atribuído principalmente à saída da placenta e ao nascimento do cordeiro. Os cordeiros jovens, por sua vez, alimentando-se quase que exclusivamente do leite materno, obtiveram GMD de $289 \mathrm{~g}$. Na avaliação seguinte, que coincidiu com o pico das parições, ainda no estádio vegetativo, houve elevada perda de peso das ovelhas, apresentando GMD de $-126 \mathrm{~g}$. Nesta data, os cordeiros mantiveram GMD de 292 g. No estádio de pré-florescimento, praticamente não houve mais parições e, por conseqüência, as perdas de peso das ovelhas, pela simples saída da placenta e pelo nascimento do cordeiro, foram desprezíveis. Assim, com forragem ainda de boa qualidade, as ovelhas tiveram ganho de peso de $87 \mathrm{~g}$ e, provavelmente, com produção de leite adequada, propiciaram aos cordeiros ótimo desempenho, com GMD de $279 \mathrm{~g}$.

Nas avaliações restantes, durante o estádio de florescimento, verificou-se GMD insatisfatório, tanto das ovelhas (-112 g) como dos cordeiros ( $89 \mathrm{~g}$ ). Esta resposta foi determinada pela provável diminuição da produção de leite das ovelhas e maior condição ruminal dos cordeiros, justamente quando a pastagem apresentava seu pior estado qualitativo.

Como resultado de todos estes indicadores, observou-se uma diferença significativa para GPV/ ha entre os três períodos analisados $(\mathrm{P}<0,05)$, sendo

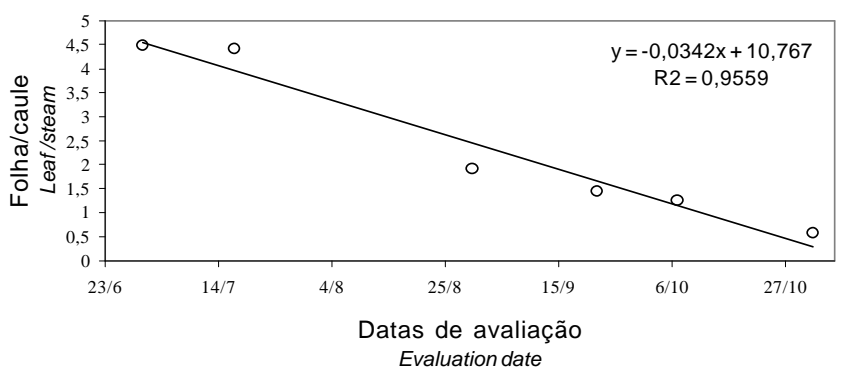

Figura 2 - Relação folha/caule para cada data de avaliação na pastagem de azevém anual.

Figura 2 - Leaf/stem ratio to each evaluation date in annual ryegrass pasture.

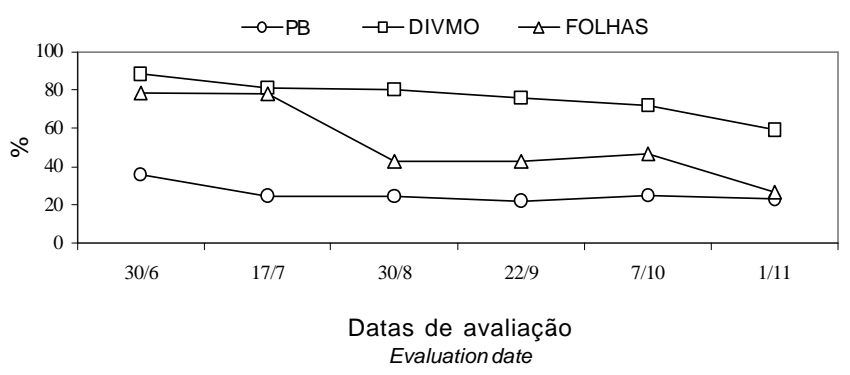

Figura 3 - Porcentagens de proteína bruta (PB), digestibilidade in vitro da matéria orgânica (DIVMO) e de folhas verdes de azevém anual durante o período de avaliação.

Figure 3 - Percentages of crude protein (CP), in vitro organic matter digestibility (IVOMD) and green leaves in annual ryegrass during the evaluation period.

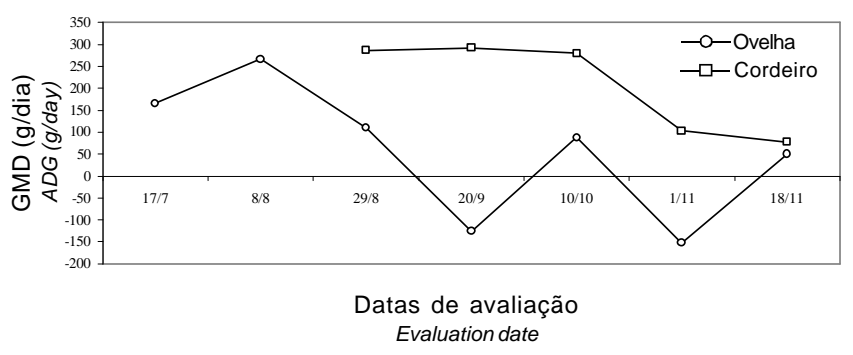

Figura 4 - Ganho médio diário (GMD) de ovelhas e cordeiros por data de avaliação em pastagem de azevém anual.

Figure 4 - Average daily gain (ADG) of ewes and lambs for each evaluation date in annual ryegrass pasture. 
de 225,145 e $1,2 \mathrm{~kg} / \mathrm{ha}$, respectivamente, em E1, E2 e E3 (Tabela 2). É importante salientar que os pesos dos cordeiros ao nascer não foram somados a estes valores, pelo fato de que estes animais não foram concebidos nem gestados na área experimental.

Na literatura, trabalhos utilizando ovelha lactante com cordeiro ao pé mostram resultados semelhantes aos aqui reportados (Prache, 1997).

Por outro lado, Slladen \& Bransby (1992), no sudeste dos Estados Unidos, Smith et al. (1986), na África do Sul, e Oliveira et al. (2001), na EEAUFRGS, em Eldorado do Sul (RS), em experimentos com cordeiros desmamados mantidos em pastagens de azevém anual, registraram ganhos de peso animal superiores aos verificados nesse experimento. Esta diferença de resposta pode ser atribuída, provavelmente, à alta capacidade de resposta dos animais jovens utilizados por aqueles autores e ao fato de os mesmos terem concentrado suas avaliações em períodos de maior qualidade da pastagem.

Assim, os valores obtidos neste trabalho comprovam que o desempenho dos ovinos durante as fases de maior exigência alimentar foi favorecido pelo acesso à pastagem de alta qualidade nos estádios vegetativo e de préflorescimento, constituindo-se em fator determinante na definição do peso dos cordeiros ao nascer $(3,86 \mathrm{~kg})$ e no elevado índice de sobrevivência $(91,5 \%)$. A partir destes dados, verifica-se a possibilidade de reduzir as elevadas perdas de cordeiros normalmente observadas no inverno a índices desprezíveis, além de propiciar às ovelhas boas condições nutricionais durante o aleitamento, sem prejuízos ao seu estado corporal, obtendo-se ao período final de utilização da pastagem, ganhos de produto animal de $371 \mathrm{~kg}$ de PV/ha.

\section{Conclusões}

A pastagem de azevém anual nos estádios vegetativo e de pré-florescimento disponibiliza alta qualidade de forragem, favorecendo o desempenho de ovelhas lactantes no momento em que suas necessidades nutricionais são mais intensas e, por conseqüência, possibilita a este rebanho maior índice de sobrevivência. Entretanto, o grande acúmulo de colmos e material morto verificado no estádio de florescimento dificulta a ação seletiva dos animais, determinando um desempenho animal insatisfatório, sendo recomendável, portanto, que estas áreas sejam destinadas para outros fins, como ressemeadura natural ou plantio de culturas de verão.

Tabela 2 - Parâmetros da pastagem e desempenho animal para cada estágio fenológico em pastagem de azevém anual

Table 2 - Pasture parameters and animal performance to each phenological stage in annual ryegrass pasture

\begin{tabular}{|c|c|c|c|c|c|c|}
\hline $\begin{array}{l}\text { Estágio } \\
\text { fenológico }\end{array}$ & & & & $\begin{array}{l}\text { Variáveis } \\
\text { Variables }\end{array}$ & & \\
\hline $\begin{array}{l}\text { Phenological } \\
\text { stage }\end{array}$ & $\begin{array}{l}\text { Oferta MS (\%PV) } \\
\text { Offer DM }(\% L W)\end{array}$ & $\begin{array}{l}\operatorname{DIVMO}(\%) \\
I V O M D(\%)\end{array}$ & $\begin{array}{l}\mathrm{PB}(\%) \\
C P(\%)\end{array}$ & $\begin{array}{l}\text { GPV(kgPV/ha) } \\
L W G(k g \quad L W / h a)\end{array}$ & $\begin{array}{c}\text { GMD } \\
\text { (ovelha/cordeiro-g/d) } \\
A D G \\
\text { (ewe/lamb-g/d) }\end{array}$ & $\begin{array}{c}\text { Carga } \\
\text { (ovelha/cord-kg PV/ha) } \\
\text { Stocking rate } \\
\text { (ewe/lamb-kg LW/ha) }\end{array}$ \\
\hline $\begin{array}{l}\text { Vegetativo } \\
\text { Vegetative }\end{array}$ & $14,98 \mathrm{a}$ & $80,55 a$ & $23,7 \mathrm{a}$ & $225,10 a$ & $103 a / 289 a$ & $848 a / 110 b$ \\
\hline $\begin{array}{l}\text { Pré-floresciment } \\
\text { Pre-flowering }\end{array}$ & $15,31 \mathrm{a}$ & $71,4 b$ & $21,2 \mathrm{ab}$ & $144,86 b$ & $87 a / 279 a$ & $868 \mathrm{a} / 282 \mathrm{a}$ \\
\hline $\begin{array}{l}\text { Florescimento } \\
\text { Flowering }\end{array}$ & $14,70 \mathrm{a}$ & $60,7 \mathrm{c}$ & $19,4 a$ & $1,16 \mathrm{c}$ & $-112 b / 89 b$ & $642 a / 269 a$ \\
\hline
\end{tabular}




\section{Literatura Citada}

ARMSTRONG, R. H.; ROBERTSON, E.; HUNTER, E. A. The effect of sward height and its direction of change on the herbage intake, diet selection and performance of weaned lambs grazing ryegrass swards. Grass and Forage Science, v.50, p.389-398, 1995.

BEATTIE, A.; THOMPSON, R. Controlled grazing management for sheep. Tasmania: Department of Agriculture, 1989. 50p.

BLASER, R.E. Symposium on forage utilization: effects of fertility levels and stage of maturity on forage nutritive value. Journal of Animal Science, v.23, p.246-253, 1964.

CANTO, M.W.; MOOJEN, E.L.; CARVALHO, P.C.F. Produção de cordeiros em pastagem de azevém e trevo branco sob diferentes níveis de resíduo da forragem. Pesquisa Agropecuária Brasileira, v.34, n.2, p.309-316, 1999.

KLINGMAN, D.L.; MILER, S.R.; MOTT, G.O. The linkage method for determination consumption and yield of pasture herbage. Journal of the American Society of Agronomy, v. 35, p. 739-746, 1943.

MELLO, O.; LEMOS, R.C.; ABRAO, P.U.R. et al. Levantamento em séries do Centro Agronômico. Revista da Faculdade Agronomia e Veterinária, v.1, p.7-155, 1966.

MOORE, K.J.; MOSER, L.E.; VOGEL, K.P. et al. Describing and quantifying growth stages of perennial forage grasses. Agronomy Journal, v.83, p.1073-1077, 1991.

MORAES, A.; MOOJEN, E.L.; MARASCHIN, G.E. Comparação de métodos de taxa de crescimento em uma pastagem submetida a diferentes pressões de pastejo. In: REUNIÃO ANUAL DA SOCIEDADE BRASILEIRA DE ZOOTECNIA, 1990, Campinas. Anais... Campinas: Sociedade Brasileira de Zootecnia, 1990. p.332.

MOTT, G.O.; LUCAS H.L. The desing, conduct, and interpretation of grazing trials on cultivated and improved pastures. In: INTERNATIONAL GRASSLAND CONGRESS. [Proceedings...] [Pensylvania : s.n.], 1952. v.6.
OLIVEIRA, J.O.R.; CARVALHO, P.C.F.; PONTES, L.S. et al. Características da carcaça de cordeiros em pastagem de azevém (Lolium multiflorum Lam.) manejadas em diferentes alturas médias. In: REUNIÃO ANUAL DA SOCIEDADE BRASILEIRA DE ZOOTECNIA, 38., 2001, Piracicaba. Anais... Piracicaba: Fundação de Estudos Agrários Luiz de Queiroz, 2001. p.185-186.

PONTES, L.S.; NABINGER, C.; CARVALHO, P.C.F. Variáveis morfogênicas e estruturais de azevém anual (Lolium multiflorum Lam.) manejado em diferentes alturas. Revista Brasileira de Zootecnia, v.32, n.4, p.814-820, 2003.

PRACHE, S. Intake rate, intake per bite and time per bite of lacting ewes on vegetetive and reproductive swards. Applied Animal Behavior Science, v.52, p.53-64, 1997.

SCALES, G.H.; BURTON, R.N.; MOSS, R.A. Lamb mortality, birthweigth and nutrition in late pregnancy. New Zealand Journal of Agricultural Research, v.29, p.75-82, 1986.

SLADDEN, S.E.; BRANSBY, D.I. Stocking rates-gain relationship for sheep and cattle on ryegrass. In: AMERICAN FORAGE GRASSLAND CONFERENCE, [Georgetown, 1992]. Proceedings... Grand rapids. [Georgetown]: American Forage Grassland Council, [1992]. p. 51-54.

SMITH, H. R.H.; BRANSBY, D.I.; TAINTON, N.M. Response of lambs to continuous and rotational grazing at four grazing intensities on Midmar Italian ryegrass. Journal of the British Grassland Society, v.2, p.56-60, 1986. 